\title{
Effects of 2-(4-Morpholinyl)-8-Phenyl-4H-1-Benzopyran-4-One on Synaptic Vesicle Cycling at the Frog Neuromuscular Junction
}

\author{
Silvio O. Rizzoli and William J. Betz \\ Department of Physiology and Biophysics, University of Colorado Medical School, Denver, Colorado 80262
}

Inositol phospholipids are thought to play an important regulatory role in synaptic membrane traffic. We investigated the effects of perturbing 3-phosphoinositide metabolism on neurotransmission at the frog neuromuscular junction. We used the reversible phosphoinositide-3 kinase (PI3K) inhibitor 2-(4-morpholinyl)-8phenyl-4H-1-benzopyran-4-one [LY294002 (LY)] and we examined its effects by intracellular recording, fluorescence imaging with styryl dyes (FM 1-43 and FM 2-10), calcium imaging, and electron microscopy. LY treatment reversibly inhibited vesicle cycling; electron micrographs indicated a dramatic reduction in the number of vesicles, balanced by the appearance of numerous cisternas. LY wash-off reverted the phenotype; terminals were refilled with vesicles, and they resumed normal FM 1-43 uptake and release. Surprisingly, $L Y$ treatment also enhanced the frequency of spontaneous release up to 100-fold in a calciumindependent manner. LY evoked similar effects in normal frog
Ringer's solution, Ca-free Ringer's solution, and BAPTA AMpretreated preparations; imaging of nerve terminals loaded with the calcium-sensitive fluorescent dye fluo-3 showed no significant change in fluorescence intensity during LY treatment. FM 1-43 imaging data suggested that LY evoked the cycling of $70-90 \%$ of all vesicles. The LY-induced effect on spontaneous release was reproduced by the casein kinase 2 inhibitor 5,6-dichlorobenzimidazole riboside but not, however, by the PI3K inhibitor wortmannin. Because LY has been shown recently to potently inhibit casein kinase 2 as well as PI3K, we hypothesize that casein kinase 2 inhibition is responsible for the enhancement of spontaneous release, whereas PI3K inhibition induces the block of vesicle cycling.

Key words: neuromuscular junction; phosphoinositide 3kinase; casein kinase 2; exocytosis; endocytosis; LY294002
Exocytosis, endocytosis, and vesicle trafficking constitute the basic steps of synaptic vesicle cycling. Inositol phospholipids, although comprising only a minor fraction of membrane lipids, have important roles in regulating vesicle cycling (for review, see Cremona and De Camilli, 2001).

The combined use of phosphoinositide-3 kinase (PI3K) inhibition and biochemical approaches led to the demonstration that PI3K activity is required at a postendocytic step in a variety of nonsynaptic trafficking pathways (Joly et al., 1995; Spiro et al., 1996; Martys et al., 1996; Odorizzi et al., 1998) (for review, see Wiedemann and Cockcroft, 1998; Stenmark and Aasland, 1999; Cockcroft and De Matteis, 2001). The PI3K-dependent block of cycling, which takes place at a stage of endosomal sorting and fusion, is thought to be dependent on the interaction between phosphatidylinositol-3-phosphate and proteins containing FYVE domains (such as the GTPase Rab-5 and early endosomal autoantigen 1; for review, see Stenmark and Aasland, 1999; Wurmser et al., 1999). However, it is unclear whether endosomal sorting and PI3K activity play important roles at the synapse (Takei et al., 1996; Murthy and Stevens, 1998).

A possible role for the products of PI3K activity in synaptic vesicle cycling has been suggested by in vitro experiments. 3-Phosphorylated inositol phospholipids have been shown to interact with a number of proteins thought to have essential roles in

Received Aug. 20, 2002; revised Oct. 3, 2002; accepted Oct. 3, 2002.

This work was supported by National Institutes of Health Research Grant 5 RO1 NS23466. We thank Steven Fadul for expert assistance in all phases of this work and Dot Dill for excellent help in electron microscopy.

Correspondence should be addressed to William J. Betz, Department of Physiology and Biophysics, C-240, University of Colorado Medical School, 4200 East Ninth Avenue, Denver, CO 80262. E-mail: bill.betz@uchsc.edu.

Copyright $\odot 2002$ Society for Neuroscience $0270-6474 / 02 / 2210680-10 \$ 15.00 / 0$ exocytosis and endocytosis, such as synaptotagmin, the putative calcium sensor of transmitter release (Schiavo et al., 1996), adaptor protein 2 (AP-2), and AP180, critical components of the clathrin-mediated endocytosis system, (Norris et al., 1995; Gaidarov et al., 1996; Hao et al., 1997). Also, at the neuromuscular junction, PI3K inhibition by wortmannin (a potent, irreversible inhibitor; Powis et al., 1994), reduced vesicular uptake of the fluorescent dye FM 1-43 by $\sim 70 \%$ (Richards and Betz, 2000), consistent with an inhibitory effect on endocytosis.

The aim of the present work was to investigate the effects of PI3K inhibition on synaptic vesicle cycling using the reversible inhibitor 2-(4-morpholinyl)-8-phenyl-4H-1-benzopyran-4-one [LY294002 LY)] (Vlahos et al., 1994). LY reversibly inhibited endocytosis and vesicle reformation, consistent with a PI3K-dependent effect. However, it also unexpectedly induced a calcium-independent increase in spontaneous release, which we were unable to reproduce using wortmannin. LY294002 has been shown recently to inhibit an unrelated protein kinase, casein kinase 2 (CK2), with potency similar to that for PI3K ( $\mathrm{IC}_{50}$ of $10 \mu \mathrm{M}$ for PI3K, $6.9 \mu \mathrm{M}$ for CK2; Davies et al., 2000). Because CK2 is a potentially important enzyme in the nervous system (for review, see Blanquet, 2000), we hypothesized that its inhibition was responsible for the LY-induced effect on spontaneous release. A specific CK2 inhibitor, 5,6-dichlorobenzimidazole riboside (DRB), induced a similar effect on release without having significant effects on endocytosis and vesicle cycling, confirming our hypothesis that PI3K inhibition results in a block of vesicle cycling, whereas CK2 inhibition potentiates spontaneous release.

\section{MATERIALS AND METHODS}

General methods. Most methods have been described previously (Betz et al., 1992; Betz and Bewick, 1992, 1993). Frog (Rana pipiens) cutaneous 
nerve-muscle preparations were dissected and mounted in SYLGARD (Dow Corning, Midland, MI)-lined chambers, filled with normal frog Ringer's solution (which contained, in mM: $115 \mathrm{NaCl}, 2 \mathrm{KCl}, 1.8 \mathrm{CaCl}_{2}$, and 5 HEPES). High-KCl solutions were prepared by elevating the extracellular $\mathrm{KCl}$ concentration with an offsetting reduction in the $\mathrm{NaCl}$ concentration to keep all solutions isotonic.

The nerve was stimulated using a suction electrode. For the recording of end plate potentials (EPPs), $\mu$-conotoxin (10 $\mu \mathrm{M}$; Calbiochem, La Jolla, CA), was added to the Ringer's solution to reduce muscle contractions. Micropipettes for intracellular recording (20-30 M $\Omega$ ), pulled with a box filament on a Flaming-Brown micropipette puller (Sutter Instruments, Novato, CA) were filled with $3 \mathrm{~m}$ potassium acetate. The signal was amplified using an Axoclamp-2A (Axon Instruments, Foster City, CA) amplifier and digitized using an MIO-16E-4 interface (National Instruments). Whole Cell Program for Windows (John Dempster, University of Strathclyde) was used for data acquisition and analysis. Recordings were rejected if the membrane potential changed by $>20 \mathrm{mV}$ or became less negative than $-60 \mathrm{mV}$.

FM dye concentrations were $3.2 \mu \mathrm{M}$ (FM 1-43) and $40 \mu \mathrm{M}$ (FM 2-10). When stimulation and imaging were performed simultaneously, curare $(10 \mu \mathrm{M})$ was added to the bath solution to prevent muscle contraction. Fluorescence images were acquired using a Nikon (Melville, NY) Optiphot upright epifluorescence microscope equipped with a Zeiss (Thornwood, NY) 63×, 0.9 numerical aperture (NA) water immersion objective lens, a $100 \mathrm{~W} \mathrm{Hg}$ lamp, 5-50\% neutral density transmission filters, excitation filters $(480 / 30$ or $540 / 25 \mathrm{~nm}$ ), dichroic mirrors (505 or $565 \mathrm{~nm}$ ), and emission filters (535/40 or $605 / 55 \mathrm{~nm}$; Chroma, Brattleboro, VT). Image acquisition was performed using a Photometrics (Tucson, AZ) SenSys cooled CCD camera. The software used for image recording was V for Windows (Digital Optics, Auckland, NZ); image analysis was performed using software custom written in MATLAB (The Mathworks, Natick, MA).

LY294002, wortmannin (Calbiochem), ionomycin, and DRB (Sigma, St. Louis, MO), prepared as stock solutions in DMSO, were added to normal frog Ringer's solution immediately before use. $\mu$-Conotoxin GIIIA (Calbiochem) was dissolved in water (5 mM), aliquoted, and stored at $-80^{\circ} \mathrm{C}$. FM 1-43, FM 2-10 (Molecular Probes, Eugene, OR), tetrodotoxin (Sigma), and curare were dissolved in water and stored at $4^{\circ} \mathrm{C}$. LY294002 was used at $200 \mu \mathrm{M}$ in all experiments, unless otherwise stated (see Results).

$\mathrm{Ca}^{2+}$ imaging. The Ca-sensitive dye fluo-3 (pentapotassium salt, cellimpermeant form; Molecular Probes) was used. The method for loading nerve terminals with fluo-3 was similar to that used for loading bullfrog sympathetic nerve terminals with membrane-impermeant fura-2 (Peng and Zucker, 1993) and has been described previously for this preparation (Wu and Betz, 1996; Angleson and Betz, 2001). Briefly, the nerve trunk was cut $1-2 \mathrm{~mm}$ before it branches into the muscle and rapidly placed in a drop of $50 \mathrm{~mm}$ fluo-3 solution. Fluo-3 was allowed to diff use into the nerve for $3-4 \mathrm{hr}$ at room temperature $\left(22-24^{\circ} \mathrm{C}\right)$; the preparation was then rinsed and incubated overnight at $4{ }^{\circ} \mathrm{C}$ in normal frog Ringer's solution. The preparation was used the following day for imaging. The loading and incubation procedures have been found previously to have no significant effect on EPP amplitude and miniature EPP (MEPP) amplitude or frequency (Wu and Betz, 1996; Angleson and Betz, 2001).

Fluo-3-loaded terminals were imaged as described above, except for the use of a Zeiss $40 \times, 0.75 \mathrm{NA}$ objective.

Electron microscopy. Muscles were fixed for $90 \mathrm{~min}$ in ice-cold fixative solution [ $2 \%$ paraformaldehyde and $2 \%$ glutaraldehyde in $0.1 \mathrm{~m}$ phosphate buffer (PB), $\mathrm{pH}$ 7.2]. After washing with $\mathrm{PB}$, the muscles were osmium-postfixed $\left(2 \% \mathrm{OsO}_{4}\right.$ in $\left.\mathrm{PB}\right)$, dehydrated through an ascending series of ethanol solutions, further dehydrated by incubation in propylene oxide, and embedded in Epon. The blocks were sectioned, and 80to 90 -nm-thick sections were collected, stained with uranyl acetate, and viewed with a Philips (Eindhoven, The Netherlands) CM10 electron microscope. Only terminals that exhibited typical active zones (identified by openings of synaptic folds) were photographed. Control preparations for each experiment consisted of the contralateral nerve-muscle preparation from the same frog, treated with the corresponding concentration of solvent.

Drosophila methods. Third instar $c n$ bw larvae (source: Maurice Kernan, State University of New York, Stony Brook, NY) were dissected; digestive and other internal organs were removed; and the CNS was removed by sectioning the nerves near the ventral ganglion (Jan and Jan, 1976). Intracellular recordings were made from body wall muscles 6 and 7 from the fourth and fifth abdominal segments. The recording solution,
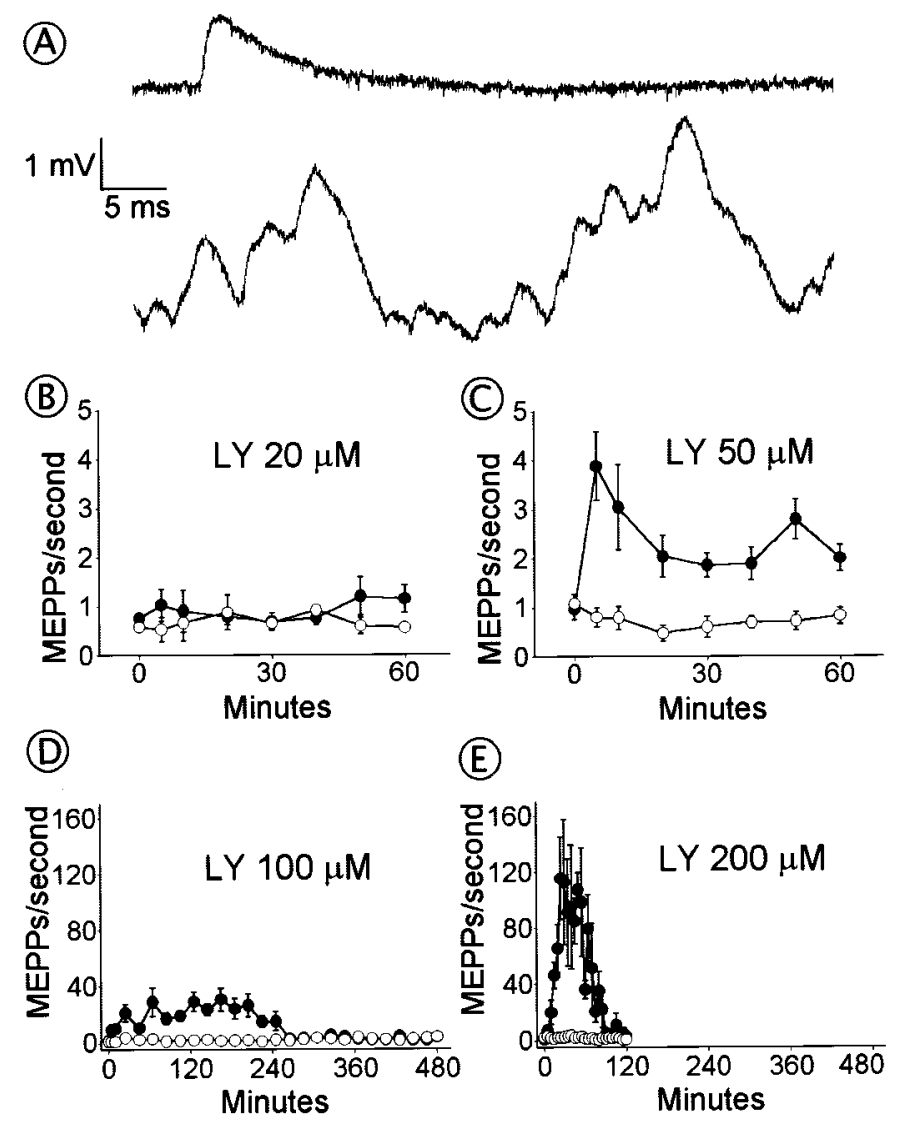

Figure 1. LY294002 enhances the frequency of spontaneous release. $A$, Traces of MEPPs from different end plates of the same preparation in the absence (top trace) or presence of $200 \mu \mathrm{M} \mathrm{LY} \mathrm{(30} \mathrm{min} \mathrm{incubation;} \mathrm{bottom}$ trace). $B-E$, Time-dependent effects of LY on the discharge of MEPPs; LY-treated end plates are indicated by filled symbols; controls are indicated by open symbols. LY concentrations: $B, 20 \mu \mathrm{M} ; C, 50 \mu \mathrm{M} ; D, 100 \mu \mathrm{M}$; $E, 200 \mu \mathrm{M}$. Shown are averages from 3-10 end plates per time point; error bars indicate SEM.

HL3 Ringer's solution (Reist et al., 1998), contained (in mM): $70 \mathrm{NaCl}$, $5 \mathrm{KCl}, 1.5 \mathrm{CaCl}_{2}, 20 \mathrm{MgCl}_{2}, 10 \mathrm{NaHCO}_{3}, 5$ trehalose, 115 sucrose, and 5 HEPES, pH 7.2. MEPP recording was performed as in the case of frog neuromuscular junction experiments (see above). For FM 1-43-imaging experiments, dissected larvae were incubated with HL3 Ringer's solution containing $200 \mu \mathrm{M}$ LY294002 or DMSO control for $2-4 \mathrm{hr}$ at room temperature and then incubated in high-potassium Ringer's solution (HL3 solution with, in mM: $30 \mathrm{KCl}$ and $45 \mathrm{NaCl}$ ) in presence of $3.2 \mu \mathrm{M}$ FM 1-43 and LY294002 or DMSO alone for 5 min. After incubation, the preparations were washed with HL3 solution at $4{ }^{\circ} \mathrm{C}$ for $45 \mathrm{~min}$ and imaged; the same imaging setup was used as in the case of frog neuromuscular junction experiments (see above).

\section{RESULTS}

\section{LY294002 caused an increase in MEPP frequency}

We tested the effect of LY294002 on the frequency of miniature events at the frog neuromuscular junction (NMJ) by incubating preparations in normal frog Ringer's (NFR) solution in the presence of the drug or the corresponding concentrations of the solvent (DMSO) as control (Fig. 1). The average MEPP frequency in untreated or solvent-treated preparations was $\sim 1 / \mathrm{sec}$. Low concentrations of the drug induced small, long-lasting increases in frequency (2-3/sec) (Fig. 1C). Higher concentrations caused frequency increases that peaked at 20-100/sec; however, the LY-induced enhancement of release was transient (Fig. $1 D, E)$. The frequency increase attained a peak at 20-30 min of 

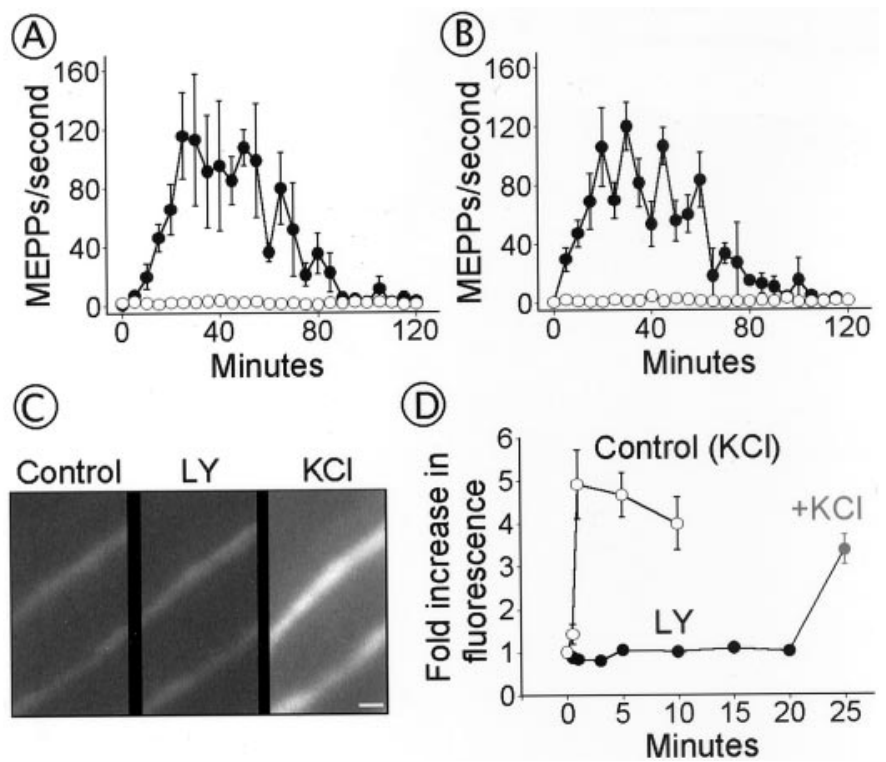

Figure 2. The LY294002-induced increase of spontaneous release is $\mathrm{Ca}^{2+}$-independent. $A$. LY-induced increase in MEPP frequency in normal frog Ringer's solution (same data as in Fig. $1 E$ ). $B$, LY-induced effects in no-added-calcium Ringer's solution (in mM: $0 \mathrm{CaCl}_{2}$ and 1.8 $\mathrm{MgCl}_{2}$ ), preparations pretreated with $100 \mu \mathrm{M}$ BAPTA AM for $2 \mathrm{hr}$ before LY incubation. LY treated end plates are indicated by filled symbols; controls are indicated by open symbols. Shown are averages of 3-10 end plates per time point; error bars indicate SEM $C$, Fluo-3 fluorescence images of BAPTA AM-pretreated nerve terminals filled with the calcium-sensitive dye fluo-3 before incubation with LY294002 (left), after $20 \mathrm{~min}$ incubation (middle), and after $30 \mathrm{~mm} \mathrm{KCl}$ in NFR solution addition (right). Scale bar, $4 \mu \mathrm{m}$. $D$, Quantification of the fluorescence increase on addition of LY ( filled symbols) and on addition of 10 $\mathrm{mM} \mathrm{KCl}$ in NFR solution to control terminals (open symbols). The gray symbol quantifies the effect of $\mathrm{KCl}$ application to the LY-treated terminals. Shown are averages from six controls and six experiments. Error bars indicate SEM. LY294002 did not induce a significant change in fluorescence $(p>0.06)$. $\mathrm{KCl}$ application induced significant increases in fluorescence in both control and LY-treated preparations ( $p$ values $<0.0001$ ), except for $30 \mathrm{sec}$ application of $10 \mathrm{~mm} \mathrm{KCl}(p<0.01)$.

incubation; after the terminals released a high number of quanta, the MEPP frequency declined, and it reached control levels. The total numbers of quanta released during LY treatment until the MEPP frequency returned to control levels were $\sim 327,000$ for $100 \mu \mathrm{M} \mathrm{LY}$ and 337,000 for $200 \mu \mathrm{M} \mathrm{LY}$, which correlates well with approximations for the total number of releasable vesicles at frog NMJ terminals (270-470,000 quanta, Heuser and Reese, 1973; Molgo and Pecot-Dechavassine, 1988; Betz et al., 1992; Van der Kloot et al., 2000; Naves and Van der Kloot, 2001).

\section{The LY294002-induced increase in MEPP frequency was $\mathrm{Ca}^{2+}$-independent}

We next investigated whether the LY-induced elevation in MEPP frequency was caused by an increase in the nerve terminal intracellular calcium concentration $\left(\left[\mathrm{Ca}^{2+}\right]_{\mathrm{i}}\right)$ (Fig. 2). We first tested whether an influx of calcium from the extracellular fluid was responsible for the LY-induced increase in MEPP frequency. We incubated preparations with $\mathrm{LY}$ in low- $\mathrm{Ca}^{2+}$ Ringer's solution (in mM: $0.26 \mathrm{CaCl}_{2}$ and $1.54 \mathrm{MgCl}_{2}$ ) or in $0-\mathrm{Ca}^{2+}$ Ringer's solution (in mM: $0 \mathrm{CaCl}_{2}, 1.8 \mathrm{MgCl}_{2}$, and 1 EGTA), recorded MEPPs, and compared results with similar experiments done in normal frog Ringer's solution (in mM: $1.8 \mathrm{CaCl}_{2}$ and $0 \mathrm{MgCl}_{2}$ ). Reducing or eliminating extracellular $\mathrm{Ca}^{2+}$ had no significant effect on the LY-induced MEPP frequency increase. The peak increase and the number of quanta released before returning to baseline levels were similar to those obtained at normal calcium levels (data not shown), suggesting that calcium influx from the extracellular fluid is not necessary for the LY effect. We next tested whether release of calcium from intracellular stores induced the rise in MEPP frequency. We preincubated neuromuscular preparations in normal frog Ringer's solution with $100 \mu \mathrm{M}$ BAPTA AM for $2 \mathrm{hr}$ at room temperature. This treatment eliminated muscle contractions in response to electrical stimulation and inhibited increases in MEPP frequency in response to 10 mM $\mathrm{KCl}$ application (data not shown), indicating efficient loading of the nerve terminals with BAPTA. The preparations were washed with frog Ringer's solution in which the added $\mathrm{CaCl}_{2}$ was replaced with $\mathrm{MgCl}_{2}$, and LY was added. The LY-induced effect on MEPP frequency was similar to the effect obtained previously with incubation in normal frog Ringer's solution (Fig. $2 A, B$ ). The number of quanta released was also similar, $\sim 310,000$.

We also tested this hypothesis by means of calcium imaging. We loaded frog NMJ nerve terminals with the calcium-sensitive dye fluo-3 and imaged them during treatments that increased MEPP frequency (Fig. 2C). Depolarization by addition of $10 \mathrm{~mm}$ $\mathrm{KCl}$, causes a calcium-dependent increase in MEPP frequency (5-10 fold in NFR solution; data not shown; Angleson and Betz, 2001). Addition of $10 \mathrm{~mm} \mathrm{KCl}$ to fluo-3-loaded preparations caused a fivefold increase in fluorescence (Fig. 2D). Addition of LY294002 to BAPTA AM-pretreated preparations (in conditions of, in mM: $0 \mathrm{CaCl}_{2}$ and $1.8 \mathrm{MgCl}_{2}$ ) causes a 100 -fold increase in MEPP frequency; however, there was no significant increase in fluo-3 fluorescence (Fig. 2D). Addition of $30 \mathrm{~mm} \mathrm{KCl}$ in NFR solution to the same terminals caused a significant increase in fluorescence, indicating viability of the cells (we used a higher level of $\mathrm{K}^{+}$to counteract the BAPTA effect).

\section{LY294002 induced the release of a large pool of vesicles}

The fact that the number of quanta released during LY treatment correlates with estimates of the total number of vesicles from frog terminals raised the hypothesis that LY incubation induces the fusion of most vesicles only once, after which the drug-induced release stops. Another hypothesis is that a relatively small pool of vesicles exocytose and endocytose repeatedly. To distinguish between these possibilities, we tetanized preparations in the presence of the fluorescent styryl dye FM 1-43, ensuring vesicular uptake of the dye, and we imaged terminals before and during LY treatment (Fig. 3A). LY-treated nerve terminals lost $\sim 70 \%$ of their fluorescence during treatment (Fig. 3B). This loss in fluorescence intensity indicates that most vesicles fused with the plasma membrane.

We then examined whether a process of membrane uptake and endocytosis compensated for the massive drug-induced exocytosis. We monitored membrane uptake by treating unstained preparations with LY294002 in the presence of FM 1-43. Significant uptake was observed after drug incubation (Fig. 3C). The terminals were brightly fluorescent but lacked the "spotty" pattern characteristic of terminals loaded via nerve stimulation or terminal depolarization by exposure to high- $\mathrm{K}^{+}$Ringer's solution (Betz et al., 1992). We compared the fluorescence intensity of the drug-treated terminals with that of terminals that had been tetanized at $30 \mathrm{~Hz}$ for $1 \mathrm{~min}$ in presence of FM 1-43 (which ensures uptake of the dye in $\sim 50 \%$ of all vesicles; Betz and Bewick, 1993). The drug-treated terminals were $\sim 1.9$ times brighter $(p<$ 

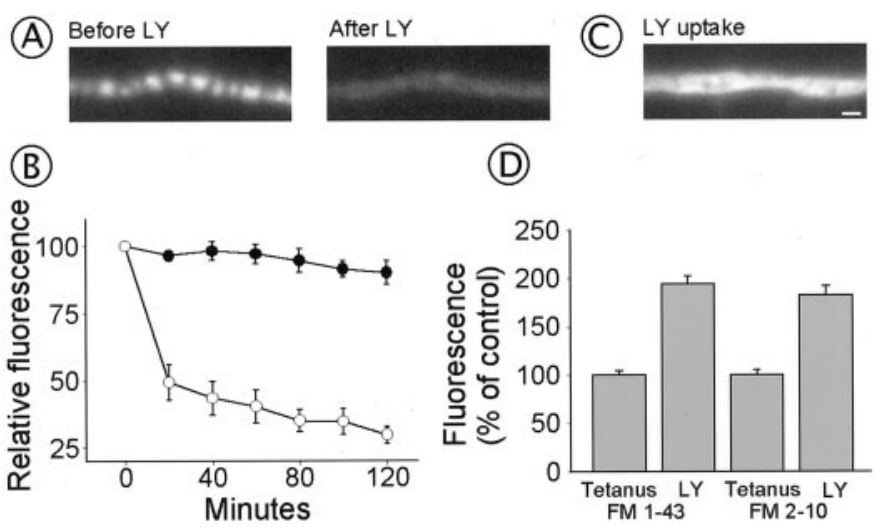

Figure 3. LY294002 induces the release and reuptake of a large pool of vesicles. $A, \mathrm{FM} 1-43$ fluorescence images of a nerve terminal preloaded with FM 1-43, before (left panel) and after (right panel) LY treatment. $B$, FM fluorescence during LY treatment (open symbols) or control (solventonly) treatment ( filled symbols); results are normalized to initial fluorescence. LY induced an $\sim 70 \%$ loss of fluorescence $(p<0.0001)$. Shown are averages from seven control terminals and seven LY-treated terminals. Error bars indicate SEM. $C$, Fluorescence image of a nerve terminal treated with LY in the presence of $3.2 \mu \mathrm{M}$ FM 1-43. Compare with the image of nerve stimulation-induced uptake (A, left panel). Scale bar $2 \mu \mathrm{M}$. $D$, Quantification of the LY-induced FM uptake $(L Y)$; for comparison, the florescence intensity of terminals that had $\sim 50 \%$ of their vesicles stained via nerve stimulation (Tetanus) is shown. Results are normalized to the fluorescence of tetanized preparations. The LY-induced fluorescence was 1.94 times brighter that that of tetanized preparations for FM 1-43 and 1.84 times brighter for FM 2-10, indicating cycling of $>90 \%$ of all vesicles. Results are shown as averages of 39-73 measurements for each treatment \pm SEM. The results obtained with FM 1-43 are not significantly different from those obtained with FM 2-10 $(p>0.3)$.

0.0001 ), suggesting that $>90 \%$ of the vesicles had undergone exocytosis and endocytosis (Fig. 3D).

One question that remained unanswered by the above experiments was whether the membrane was fully internalized during cycling in the presence of the drug. Formation of infoldings that remain open to the extracellular fluid could have compensated for the increase in membrane surface after exocytosis. Such infoldings would have trapped the dye we used, FM 1-43, because of its relatively high hydrophobicity; however, a more hydrophilic analog, FM 2-10, is believed to be able to escape from membrane infoldings (Richards et al., 2000). To test whether "open" infoldings play a role in drug-induced cycling, we repeated the above uptake experiments using the FM 2-10 dye. The drug-treated terminals were 1.84 times brighter than terminals stained via nerve stimulation (Fig. $3 D$ ). The results were not significantly different from those obtained with FM 1-43 ( $p>0.3)$, suggesting complete internalization of the dye-stained membrane.

\section{LY294002 inhibited electrically stimulated vesicle cycling}

We investigated the LY effect on stimulated release (Fig. 4). The muscle nerve was drawn into a suction electrode; we applied 2-msec-long square pulses at 5-20 min intervals and recorded EPPs. To inhibit muscle contractions, we added to the recording solution $10 \mu \mathrm{M} \mu$-conotoxin GIIIA, a specific inhibitor of muscle, but not nerve, sodium channels. LY addition induced a rapid inhibition in EPP amplitude (Fig. 4A). After 30-40 min of incubation, EPP amplitude was undetectable, indicating a complete block of induced release at the time when the frequency of spontaneous release attains a plateau (Fig. 4B).
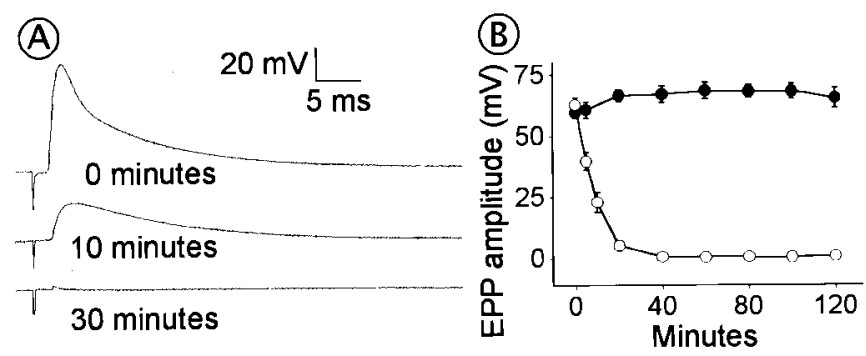

Figure 4. LY294002 potently inhibits evoked stimulation. A, Typical EPP traces from different end plates in the same preparation in the presence of $\mu$-conotoxin. Top trace, before LY treatment; middle trace, 10 min LY treatment; bottom trace, 30 min LY treatment. B, Quantification of the time-dependent LY effect (open symbols) versus control (filled symbols); results show averages of 7-15 measurements per time point; error bars indicate SEM.
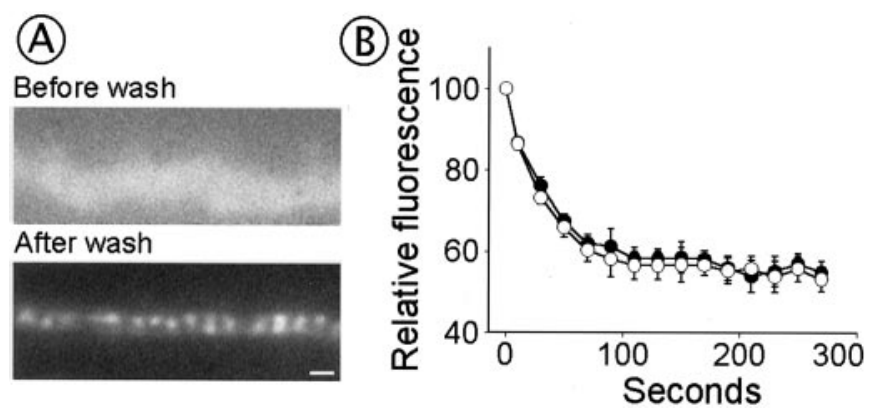

Figure 5. The LY294002 block of induced cycling is reversible. A, Fluorescence images of terminals electrically stimulated in the presence of FM 1-43 immediately after LY treatment (top panel, imaged with $100 \%$ mercury lamp intensity) or after $12 \mathrm{hr}$ of washing at $4^{\circ} \mathrm{C}$ in NFR solution (bottom panel, imaged with 25\% mercury lamp intensity). Scale bar, $2 \mu \mathrm{m}$. $B$, Quantification of FM 1-43 release on tetanic stimulation in control (open symbols) and LY-treated and washed (filled symbols) terminals. Shown are averages of seven measurements \pm SEM. Results are normalized to initial fluorescence.

\section{The LY294002-induced block of cycling was reversible}

As expected from the decline in EPP amplitude, electrical stimulation after $2 \mathrm{hr}$ of LY treatment was unable to induce FM uptake or release (results not shown), confirming a block of stimulation-induced vesicle cycling. The staining obtained exhibited $<5 \%$ of control preparation intensity and lacked the normal pattern induced by vesicle clusters (Fig. 5A). Because LY294002 is considered a reversible enzymatic inhibitor (it reversibly contacts the ATP-binding site of PI3K and related enzymes, stopping the access of ATP; Walker et al., 2000), we investigated whether its blocking effects on vesicle cycling were reversible (Fig. 5). We treated NMJ preparations with LY for $2 \mathrm{hr}$, which ensured almost complete block of stimulation-induced cycling. We then washed the preparations in normal frog Ringer's solution at $4^{\circ} \mathrm{C}$. Washing at low temperature reduces the metabolism of the preparation (and possibly increases the recovery time from the drug effects), but it ensures its viability for long periods. Washing the preparation overnight completely reversed the inhibition of vesicle cycling. Tetanic stimulation in the presence of FM 1-43 resulted in dye uptake that was indistinguishable from that of controls (Fig. $5 A$, bottom panel). Quantification of the uptake indicated complete recovery of endocytosis (before LY wash-off, terminals took up $\sim 3.5 \pm 0.85 \%$ of control fluorescence; after wash-off, they took up $98.71 \pm 6.52 \%$; not significantly different from control, $p>0.5)$. We also tested whether these terminals were able to 
Figure 6. LY294002 reversibly induces vesicle depletion at the frog NMJ. $A$, Electron microscopic images of nerve terminals treated with solvent only (left panel), with LY for $2 \mathrm{hr}$ (middle panel), and with LY for $2 \mathrm{hr}$ followed by LY wash-off (right panel). Scale bar, $200 \mathrm{~nm}$. $B$, Percentage of the terminal crosssectional area occupied by vesicles ( filled symbols) or cisternae (open symbols) during LY treatment. $C$, Percentage of the terminal area occupied by vesicles (filled symbols) or cisternae (open symbols) during LY wash-off. Asterisks indicate values not significantly different from those of controls $(p>$ $0.1)$. $D$, Quantification of the LY effects on the proportion of vesicles and cisternae in solutions containing normal calcium (NFR solution); (in mm): $0.26 \mathrm{Ca}$

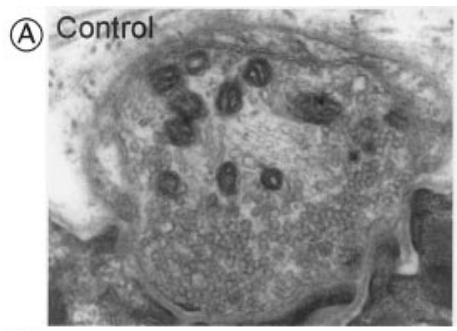

(B)

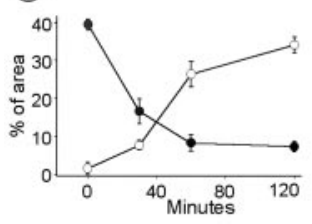

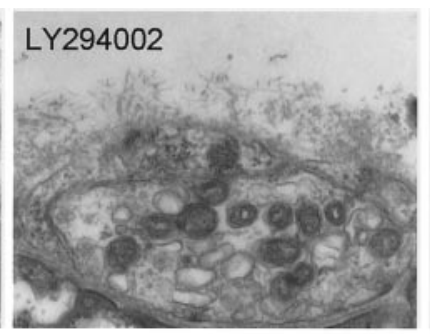

(D)

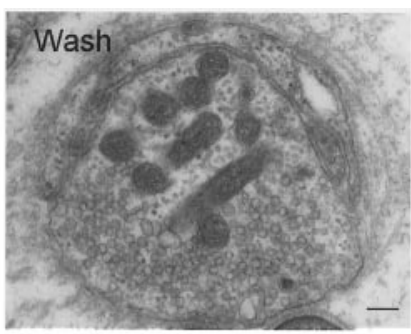

(E)

and 1.54 Mg (low-calcium Ringer's solution); (in mM): $0 \mathrm{Ca}, 1.8 \mathrm{Mg}$, and 1 EGTA (EGTA Ringer's solution); or (in mM) $0 \mathrm{Ca}$ and $1.8 \mathrm{Mg}$, after incubation with $100 \mu \mathrm{M}$ BAPTA AM. Results are presented as percentage of cross-sectional terminal area occupied by vesicles (circles) and cisternae (triangles) in control (open symbols) or LY-treated ( filled symbols) preparations. Vesicle depletion is not affected by calcium removal. However, cisterna formation was significantly impaired in EGTA-treated terminals, as opposed to NFR solution-treated terminals $(p<0.0001)$. E, Quantification of presynaptic membrane length for LY-treated terminals ( filled symbols) or solvent-only-treated terminals (open symbols) in different calcium conditions. The membrane length was significantly higher in LY-treated preparations only in the case of EGTA treatment $(p<0.001)$, suggesting that EGTA treatment impaired cisterna formation from the plasma membrane. All results are shown as averages of 20-45 measurements \pm SEM.

release the dye on stimulation. Figure $5 B$ quantifies results from seven LY-treated terminals and seven controls; the data indicate that the terminals also recovered their ability to exocytose.

\section{Ultrastructural effects of LY294002}

We examined the ultrastructure of nerve terminals during LY treatment (Fig. 6). We observed marked depletion of synaptic vesicles (Fig. 6A, middle panel, quantified in $B$ ). Quantification of the data indicated that $>80 \%$ of all vesicles disappeared during LY treatment. Incubation with solvent alone did not induce significant changes in terminal ultrastructure (results not shown). The decrease in the vesicle membrane was balanced by the appearance of a large number of irregularly shaped, membranewalled objects of a larger size than vesicles, which we termed cisternae, in agreement with previous work (Heuser and Reese, 1973). There was no significant difference between the membrane area of drug-treated terminals and that of control terminals (data not shown).

We also investigated whether the drug-induced vesicle depletion was reversible. Washing preparations resulted in complete reversal of the phenotype (Fig. $6 \mathrm{C}$ ); the cisternae disappeared, and the terminals were replenished with vesicles. Vesicle reformation appears to have involved formation of clathrin-coated vesicles; $44.16 \pm 5.46 \%$ of all terminals investigated during washing and vesicle reformation (1-12 hr) contained coated vesicles; only $6.44 \pm 3.14 \%$ (mean \pm SEM) of the control terminals contained coated vesicles; and only one section (80-90 nm thickness) was investigated per terminal.

We tested whether calcium removal influenced the depletion of vesicles or the formation of cisternae. We exposed preparations to LY in different calcium conditions: we lowered extracellular calcium (low- $\mathrm{Ca}^{2+}$ Ringer's solution); we abolished extracellular calcium (0-Ca ${ }^{2+}$ Ringer's solution); or we treated preparations with BAPTA AM before incubation in Ringer's solution with no added calcium. In all experiments, vesicle depletion was similar to that obtained in normal calcium conditions (Fig. 6D). Formation of cisternae was also not significantly different from that of normal calcium conditions except for EGTA treatment. In $1 \mathrm{~mm}$ EGTA Ringer's solution, LY treatment depleted vesicles and significantly increased the proportion of cisternae but not to the level attained in normal calcium Ringer's solution. The membrane area in this case was significantly higher than for the solvent-treated controls $(p<0.001)$ (Fig. $6 E)$, suggesting that EGTA treatment partially inhibited (slowed) cisterna formation from the plasma membrane.

\section{Low concentrations of LY294002 also inhibited FM dye uptake and vesicle reformation}

We wondered whether the LY-induced effects on exocytosis and endocytosis had different concentration dependencies. We first tested the effects of 20,50, and $100 \mu \mathrm{M} \mathrm{LY}$ on vesicle recycling by monitoring the FM 1-43 uptake. Twenty micromolar LY did not induce a significant effect on FM uptake $(p>0.1)$. After 60 min of incubation, the FM 1-43 uptake was significantly inhibited by concentrations of 50 and $100 \mu \mathrm{M}$. The fluorescence of drugtreated terminals was down to $84 \pm 3.6$ and $73.8 \pm 3.5 \%$ (average $\pm \mathrm{SEM})$ of that of control terminals, respectively. The decrease was significant $(p<0.02)$. Longer incubations with $100 \mu \mathrm{M}$ LY induced further reductions in FM uptake; after $8 \mathrm{hr}$ of incubation, uptake was down to $20.7 \pm 3.62 \%$ of controls $(p<0.01)$.

We also investigated the effects of low concentrations of LY on vesicle reformation. In our first experiment, we incubated preparations with 20 or $50 \mu \mathrm{M} \mathrm{LY}$ for $60 \mathrm{~min}$. The lower concentration did not induce significant differences in terminal structure (data not shown); however, incubation with $50 \mu \mathrm{M} \mathrm{LY}$ doubled the levels of cisternae in the terminals (from $0.92 \pm 0.16 \%$ of the terminal surface to $1.97 \pm 0.46 \% ; p<0.05$ ).

We also investigated the effect of low concentrations of LY on stimulation-induced vesicle recycling. We incubated preparations for 60 min with $20-50 \mu \mathrm{M} \mathrm{LY}$, stimulated them in the presence of the drug for $1 \mathrm{~min}$ at $30 \mathrm{~Hz}$, and allowed them to recover for 15 min. Twenty micromolar LY induced a significant increase in the levels of cisternae (from $0.98 \pm 0.24 \%$ of the terminal surface to $1.97 \pm 0.34 \% ; p<0.05)$. Fifty micromolar LY induced not only an increase in the levels of cisternae (from $1.36 \pm 0.33 \%$ of the terminal surface to $8.01 \pm 1.70 \% ; p<0.01$ ) but also a significant depletion of vesicles (from $42.77 \pm 2.87 \%$ of the terminal surface to $32.94 \pm 3.39 \%$ of the terminal surface; $p<0.05$ ). 


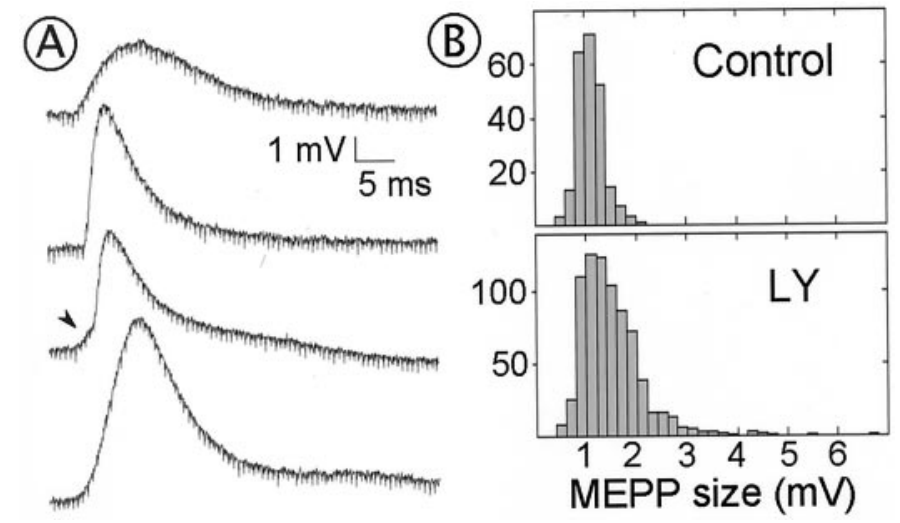

Figure 7. Giant MEPPs appear during LY294002 wash-off. A, Typical traces of giant MEPPs from LY-treated and washed preparations. The arrow indicates a discrete step in the rising phase of a giant event. $B$, Amplitude distribution of MEPPs in untreated (top) and LY-treated and washed (bottom) end plates. Two hundred twenty-eight control MEPPs and 767 experimental MEPPs were analyzed.

These results suggest that the low LY concentrations that have small but significant effects on MEPP frequency (Fig. 1) also inhibit membrane recycling.

\section{LY294002 wash-off was accompanied by the appearance of giant MEPPs}

A number of treatments that cause sustained release of the neurotransmitter at the frog NMJ are followed by the appearance of "giant" MEPPs (for example, lanthanum stimulation; Heuser, 1974). Giant miniature events are thought to be a result of large acetylcholine-containing, membrane-bound bodies fusing with the plasma membrane (Heuser, 1974; Heinonen et al., 1982; Hawgood et al., 1988; Sellin et al., 1996). However, the hypothesis of giant events resulting from synchronized release of a number of quanta is embraced by some authors (Vautrin and Kriebel, 1991, 1997).

During recovery from massive release, for example, from long tetani (15 $\mathrm{min}$ at $10 \mathrm{~Hz}$; Heuser, 1974) or from $\mathrm{KCl}$ depolarization (42 mм for $30 \mathrm{~min}$; Molenaar et al., 1987), giant spontaneous events are observed. Similarly we observed large MEPPs during recovery from LY treatment (a few examples in Fig. 7A). Histograms of MEPP size show an increase in larger-than-average MEPPs in LY-treated preparations during recovery (Fig. 7B).

Giant MEPPs were not affected by tetrodotoxin treatment (results not shown), eliminating the possibility that the large release events are caused by the synchronous fusion of a number of vesicles triggered by spontaneous action potentials. Giant MEPP formation as a result of random spontaneous fusion of a number of quanta is also possible. However, giant MEPPS with amplitudes of 3-12 $\mathrm{mV}$ appeared with frequencies of $0.5-2 / \mathrm{sec}$ at fibers having low total MEPP frequencies (1-5/sec), suggesting that this explanation was unlikely. The presence of numerous large vesicles during LY wash-off also suggests that the giant MEPPs observed are caused by single, large neurotransmittercontaining bodies. Some giant MEPPs exhibited discreet steps in the rising phase, which may reflect fusion pore opening and subsequent dilation (Fig. 7A, arrow).

Few giant MEPPs were observed before washing preparations. The frequency of giant MEPPs was $\sim 1.34 \pm 0.27$ (mean \pm SEM) after $1 \mathrm{hr}$ of washing, and it slowly declined: $1.03 \pm 0.15$ at $4 \mathrm{hr}$ of washing, $0.88 \pm 0.18$ at $7 \mathrm{hr}$ of washing, and $0.42 \pm 0.07$ at 24 hr of washing, consistent with the disappearance of large, abnormal vacuoles observed in the electron microscopic experiments.

Giant MEPPs are thought to be generated by constitutive secretion, independent of the $\left[\mathrm{Ca}^{2+}\right]_{\mathrm{i}}$ (Hawgood et al., 1988; Alkadhi, 1989; Sellin et al., 1996). We inquired whether the LY treatment-induced giant MEPPs were $\mathrm{Ca}^{2+}$-inducible. According to the histograms (Fig. $7 B$ ), we defined miniature events of $>2.5 \mathrm{mV}$ as giant MEPPs. We measured normal and giant MEPP frequencies at five LY-treated nerve terminals before and after addition of the calcium ionophore ionomycin. Ionomycin $(0.5 \mu \mathrm{M})$ addition induced a $2.86 \pm 0.48$-fold increase in normal MEPP frequency $(p<0.005)$. As expected, there was no significant increase in the frequency of giant MEPPs $(1.08 \pm 0.14$-fold increase; $p>0.5)$.

\section{DRB mimicked the LY294002 effect on MEPP frequency}

The irreversible PI3K inhibitor wortmannin (Powis et al., 1994; Wymann et al., 1996) has a similar effect on inhibiting vesicle cycling and reformation, (D. A. Richards and W. J. Betz, unpublished electronic microscopic data). However, wortmannin (0.1$100 \mu \mathrm{M}$ ) does not induce an increase in MEPP frequency (results not shown), suggesting that LY may act not only on PI3K but also on another enzyme. LY is generally considered to be a specific PI3K inhibitor (Vlahos et al., 1994) (for review, see Stein and Waterfield, 2000), but Davies et al. (2000) showed in in vitro experiments that it also inhibits CK2 with a potency similar to that for PI3K. Because CK2 has been shown to phosphorylate a number of proteins involved in vesicle fusion (synaptotagmin and syntaxin; Bennett et al., 1993; Davletov et al., 1993; Hilfiker et al., 1999; Risinger and Bennett, 1999), we hypothesized that the LY effect on MEPP frequency was induced by a block of CK2. To test that hypothesis, we used the CK2-specific inhibitor DRB (Zandomeni et al., 1986; Meggio et al., 1990; Szyszka et al., 1995). Because of its riboside moiety, it is only weakly cell-permeant; concentrations of 200-1000 $\mu \mathrm{M}$ have been used in in vivo experiments (Kim and Kahn, 1997; Delalande et al., 1999; Hidalgo et al., 2001). We incubated preparations with $300 \mu \mathrm{M}$ DRB to test its effect on the frog NMJ (Fig. 8); larger concentrations of the drug induced the formation of a white crystalline precipitate under our experimental conditions.

DRB addition induced an increase in the frequency of miniature events (Fig. 8A,B). The average DRB-induced increase in MEPP frequency was $12.48 \mathrm{MEPPs} / \mathrm{sec}$, with an SD of 16.82; the increase was statistically significant $\left(p<10^{-10}\right)$.

We also tested whether the DRB effect was dependent on an increase in the $\left[\mathrm{Ca}^{2+}\right]_{\mathrm{i}}$ of the nerve terminals. As for the LY experiments, we pretreated preparations with $100 \mu \mathrm{M}$ BAPTA AM (2 hr at room temperature, NFR solution), and we incubated them with DRB in a solution containing no added calcium. The DRB effect was unaffected (Fig. 8C). There was no significant difference between the MEPP frequency in the presence of DRB in preparations in normal calcium conditions or in solutions lacking calcium $(p>0.98)$, indicating that the DRB-induced effect was calcium-independent.

We also investigated the DRB effect on vesicle cycling. We incubated preparations with DRB for $1-3 \mathrm{hr}$ and then tetanized them for $1 \mathrm{~min}$ at $30 \mathrm{~Hz}$ in the presence of FM 1-43. The DRB-treated nerve terminals were indistinguishable from controls (results not shown). We quantified the amount of fluorescence from control and DRB-treated terminals; DRB-treated preparations exhibited a small $(\sim 12 \%)$ increase in fluorescence 

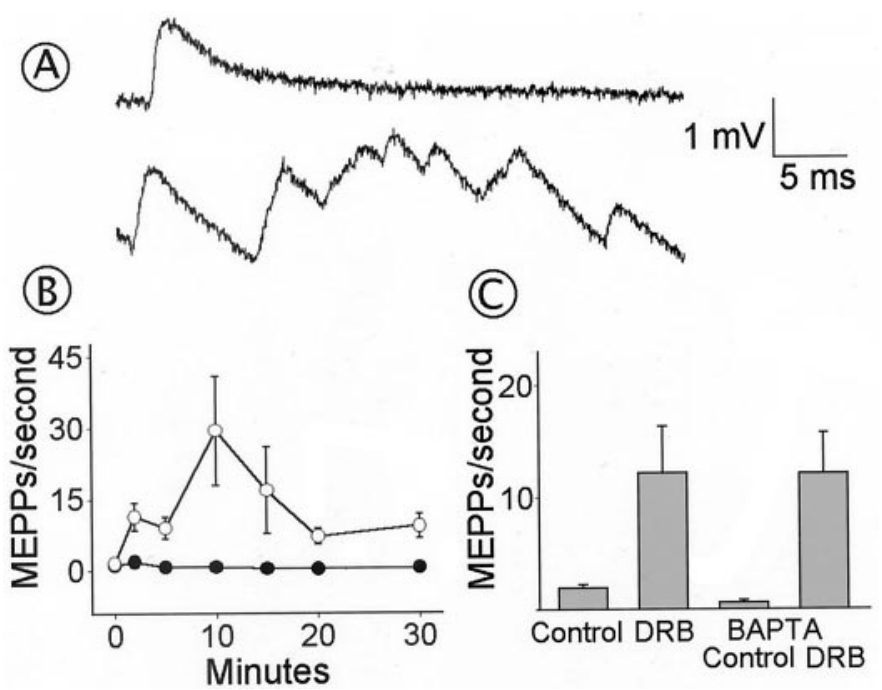

Figure 8. The CK2 inhibitor DRB induces a calcium-independent increase in MEPP frequency without affecting vesicle recycling. $A$, Traces of MEPPs from different end plates of the same preparation in the absence (top trace) or presence (bottom trace) of $300 \mu \mathrm{M}$ DRB (10 min incubation). $B$, Time-dependent effect of $300 \mu \mathrm{M}$ DRB on MEPP frequency. Results are shown as averages of 7-10 measurements for each time point \pm SEM $C$, MEPP frequency before and after DRB addition in normal calcium conditions (left) or BAPTA AM-pretreated preparations in a solution of (in mm): $0 \mathrm{CaCl}_{2}$ and $1.8 \mathrm{MgCl}_{2}$. Results are shown as averages of 14-23 measurements \pm SEM. DRB induced significant increases in MEPP frequency in both NFR solution and BAPTA pretreatment conditions ( $p<0.05$ and 0.01 , respectively). The DRB-induced MEPP frequency increase was not significantly affected by BAPTA AM pretreatment $(p>0.98)$.

that was not statistically significant ( $p>0.12 ; 30$ control and 32 LY-treated terminals were analyzed). These results indicate that DRB had no significant effect on stimulation-evoked vesicle cycling.

\section{LY294002 increased MEPP frequency at the Drosophila neuromuscular junction}

We investigated whether the LY-induced increase in spontaneous release that we observed at the frog NMJ was reproducible at the Drosophila neuromuscular junction. We incubated third instar larval preparations of Drosophila with LY, and we recorded MEPPs from abdominal muscle fibers 6 and 7. LY significantly increased the rate of spontaneous release. The control frequency was $1.37 \pm 0.28 \mathrm{MEPPs} / \mathrm{sec}$ (12 fibers, mean $\pm \mathrm{SEM}$ ), and it increased in presence of LY to $3.83 \pm 0.73 \mathrm{MEPPs} / \mathrm{sec}$ (8 fibers; $p<0.003$ ). However, LY did not reduce significantly the amount of FM 1-43 loading on stimulation (data not shown), indicating a lack of effect on vesicle recycling, possibly because of a limited inhibitory action of LY on Drosophila kinases.

\section{DISCUSSION}

Our results show that LY induces a calcium-independent increase in spontaneous neurotransmitter release, whereas it inhibits electrically stimulated release. LY treatment reversibly blocks membrane cycling; electron microscopic data demonstrate an accumulation of cisternal membrane, suggesting that cycling is inhibited at a step after endocytosis but before vesicle reformation.

Among the PI3K inhibitors, the most studied are wortmannin and LY294002. They are considered more specific than most other drugs that inhibit PI3K (such as demethoxyviridiin, quercetin, myricetin, and staurosporine; Stein and Waterfield, 2000;
Walker et al., 2000). The two drugs induce similar effects in a variety of systems; there are only a limited number of reports of differences between their activities (Salh et al., 1998; Adi et al., 2001). At the frog neuromuscular junction, wortmannin was unable to reproduce the LY-induced increase in MEPP frequency. However, it reproduced the inhibition of FM dye uptake (Richards and Betz, 2000), even at very low concentrations (50\% inhibition by $10 \mathrm{~nm}$ wortmannin); also, preparations tetanized in the presence of wortmannin are depleted of vesicles, which are replaced by larger membrane-bound objects (Richards and Betz, unpublished electron microscopic observations). These results suggest that the observed block of membrane cycling is PI3Kdependent, whereas the increase in spontaneous release is not.

However, the concentration dependencies of the two effects of LY were similar. Davies et al. (2000) demonstrated that LY, but not wortmannin, inhibits CK2 with a potency similar to that for $\mathrm{PI} 3 \mathrm{~K}$. The CK2 inhibitor DRB induced an increase in spontaneous release, resembling that caused by LY. It did not have a significant effect on vesicle cycling. These results suggest that PI3K inhibition results in a block of membrane cycling, whereas CK2 inhibition potentiates spontaneous release in a calciumindependent manner.

\section{$\mathrm{Ca}^{2+}$-independent enhancement of spontaneous release induced by CK2 inhibition}

Data obtained from light microscopic, electron microscopic, and electrophysiologial experiments give an estimate of 70-90\% of all vesicles being released during LY treatment independent of the calcium concentration. Only a few types of treatment have been demonstrated to enhance transmitter release in a calciumindependent manner. Hypertonic potentiation of transmitter release (Fatt and Katz, 1952; Hubbard et al., 1968; Doherty et al., 1986; Kashani et al., 2001) has been shown to be calciumindependent. However, unlike LY treatment, it affects only a small pool of vesicles, being actually used to define a "readily releasable" pool of vesicles (Stevens and Tsujimoto, 1995; Rosenmund and Stevens, 1996). Similarly, ruthenium red has been shown to enhance spontaneous transmitter release independent of $\mathrm{Ca}^{2+}$. It also affects only a small, readily releasable pool of vesicles; exocytosis of predocked vesicles is directly triggered by ruthenium red binding to the presynaptic membrane, a process that is inhibited by heparin (Trudeau et al., 1996; Sciancalepore et al., 1998; Congar and Trudeau, 2002). $\alpha$-Latrotoxin has also been proposed to induce $\mathrm{Ca}^{2+}$-independent release of classic neurotransmitters but not catecholamines (for review, see Südhof, 2001), but recent data suggest that $\mathrm{Ca}^{2+}$ release from intracellular stores coupled with $\mathrm{Ca}^{2+}$ entry through $\alpha$-latrotoxin pores in the membrane plays an important role in latrotoxin-induced release of neurotransmitters (Ashton et al., 2000, 2001; Tsang et al., 2000).

Synaptic transmission is usually thought of as a result of calcium-regulated release of a neurotransmitter. Although there is no consensus on how calcium influx induces release at the molecular level, a current view is that calcium signals are transduced by a family of vesicle membrane proteins, synaptotagmins (for review, see Littleton and Bellen, 1995; Geppert and Südhof, 1998). Synaptotagmins undergo conformational changes in response to calcium, and their interactions with a number of presynaptic proteins and phospholipids change, allowing for vesicle fusion (Augustine, 2001).

Synaptotagmin mutations or deletions in Drosophila induce an increase in spontaneous transmitter release as well as a reduction 
of stimulation-induced release (DiAntonio et al., 1993; Littleton et al., 1993, 1994; Reist et al., 1998). We observed a threefold increase in Drosophila MEPP frequency on LY addition, similar to that obtained in synaptotagmin-null preparations (Reist et al., 1998; Loewen et al., 2001).

Schiavo et al. (1996) demonstrated that synaptotagmin I binds phosphatydilinositol-3,4,5-triphosphate (PIns-3,4,5-P3) at low calcium concentrations, similar to those found in resting cells. An increase in calcium concentration to the levels required for transmitter release switches synaptotagmin binding to phosphatydilinositol-4,5-diphosphate (PIns-4,5-P2), the product of PIns3,4,5-P3 dephosphorylation. Inhibition of PI3K decreases the concentration of the 3-phosphorylated form, possibly providing an opportunity for PIns-4,5-P2 binding by synaptotagmin and its switch to the fusion-allowing form. It is, however, unlikely that this hypothesis accounts for the LY-induced increase in MEPP frequency, because PI3K inhibition by wortmannin results in no significant increase in spontaneous release (data not shown).

CK2 is a ubiquitous, constitutively active, calcium- and cyclic nucleotide-independent protein kinase (for review, see Tuazon and Traugh, 1991), which is also present on synaptic vesicles. It has been shown to phosphorylate a number of proteins thought to be involved in vesicle fusion: vesicle-associated membrane protein and synaptobrevin (Nielander et al., 1995), syntaxin-4 (Foster et al., 1998), syntaxin-1A (Risinger and Bennett, 1999), but especially synaptotagmin (Bennett et al., 1993; Davletov et al., 1993; Hirling and Scheller, 1996; Hilfiker et al., 1999). Also, Bennett et al. (1993) demonstrated an in vivo interaction between synaptotagmin and CK2, because immunoprecipitation of the former results in coprecipitation of the latter.

On the basis of these results, we hypothesize that casein kinase inhibition by LY or DRB induces an increase in MEPP frequency via perturbation of synaptotagmin function.

\section{PI3K-dependent inhibition of membrane cycling}

The classic model of vesicle recycling postulates that after exocytosis (synaptic vesicle coalescing with the plasma membrane), equal amounts of membrane are retrieved by clathrin-coated vesicles arising directly from the plasma membrane. The coated vesicles then lose their coats and coalesce to form cisternae, which will slowly divide and form new synaptic vesicles (Heuser and Reese, 1973).

However, a different mechanism for membrane retrieval has been shown to participate in endocytosis after intense release at nerve terminals: formation of deep infoldings and large cisternae, known as bulk endocytosis (Miller and Heuser, 1984; Takei et al., 1996; Richards et al., 2000). The cisternae formed are proposed to break into vesicles via clathrin coat-mediated budding, in parallel with budding from the plasma membrane. Bulk endocytosis accounts for a large fraction of membrane uptake $(80 \%$ according to Richards et al., 2000).

Clathrin coat formation is believed to begin with binding to membrane proteins and lipids of AP-2 and AP180. The adaptors then bind clathrin and promote coat assembly (Cremona and De Camilli, 1997; Brodin et al., 2000). Synaptotagmins also bind AP-2 with high affinity, and expression of synaptotagmin lacking the AP-2-binding domain inhibits endocytosis in a cell culture system (von Poser et al., 2000).

Inositol phospholipids have been shown to have important roles in clathrin coat-mediated reformation of vesicles (Cremona and De Camilli, 2001). AP-2, AP180, and synaptotagmin have all been shown to interact with 3-phosphorylated inositol phospho- lipids. AP-2 has been shown to bind PIns-3,4,5-P3 with high affinity (Gaidarov et al., 1996), and the phosphoinositide interaction has been demonstrated to be essential for targeting of AP-2 to coated pits (Gaidarov and Keen, 1999) and for AP-2 interaction with many plasma membrane proteins (Rapoport et al., 1997). Synaptotagmin interacts with PIns-3,4,5-P3 (see above), and so does AP180 (Norris et al., 1995; Hao et al., 1997).

Another perspective on the role of PI3K in endocytosis emerged recently when Domin et al. (2000) discovered that the class II PI3K-C $2 \alpha$ can be copurified with clathrin-coated vesicles from bovine brain. A subsequent paper from the same group (Gaidarov et al., 2001) indicated that PI3K-C2 $\alpha$ binds directly to clathrin, and that clathrin binding enhances its catalytic activity, especially toward PIns-4,5-P2.

These findings suggest a role for PI3K in vesicle formation via the clathrin coat pathway at the synapse, after the step of cisternae formation from bulk endocytosis. This hypothesis explains the accumulation of cisternae and irregular membranous objects in LY-treated terminals as well as in wortmannin-treated terminals (Richards and Betz, unpublished observations). It also explains the significant increase in the number of coated vesicles and pits observed during LY wash-off.

Our experiments provide the first in vivo data suggesting important regulatory roles for PI3K and CK2 in vesicle cycling at the neuromuscular junction, confirming previous conclusions obtained from biochemical and genetic investigations.

\section{REFERENCES}

Adi S, Wu NY, Rosenthal SM (2001) Growth factor-stimulated phosphorylation of Akt and p70(S6K) is differentially inhibited by LY294002 and wortmannin. Endocrinology 142:498-501.

Alkadhi KA (1989) Giant miniature end-plate potentials at the untreated and emetine-treated frog neuromuscular junction. J Physiol (Lond) 412:475-491.

Angleson JK, Betz WJ (2001) Intraterminal $\mathrm{Ca}^{2+}$ and spontaneous transmitter release at the frog neuromuscular junction. J Neurophysiol $85: 287-294$

Ashton AC, Rahman MA, Volynski KE, Manser C, Orlova EV, Matsushita H, Davletov BA, van Heel M, Grishin EV, Ushkaryov YA (2000) Tetramerisation of alpha-latrotoxin by divalent cations is responsible for toxin-induced non-vesicular release and contributes to the $\mathrm{Ca}^{2+}$ dependent vesicular exocytosis from synaptosomes. Biochimie 82:453-468.

Ashton AC, Volynski KE, Lelianova VG, Orlova EV, Van Renterghem C, Canepari M, Seagar M, Ushkaryov YA (2001) alpha-Latrotoxin, acting via two $\mathrm{Ca}^{2+}$-dependent pathways, triggers exocytosis of two pools of synaptic vesicles. J Biol Chem 276:44695-44703.

Augustine GJ (2001) How does calcium trigger neurotransmitter release? Curr Opin Neurobiol 11:320-326.

Bennett MK, Miller KG, Scheller RH (1993) Casein kinase II phosphorylates the synaptic vesicle protein p65. J Neurosci 13:1701-1707.

Betz WJ, Bewick GS (1992) Optical analysis of synaptic vesicle recycling at the frog neuromuscular junction. Science 255:200-203.

Betz WJ, Bewick GS (1993) Optical monitoring of transmitter release and synaptic vesicle recycling at the frog neuromuscular junction. J Physiol (Lond) 460:287-309.

Betz WJ, Mao F, Bewick GS (1992) Activity-dependent fluorescent staining and destaining of living vertebrate motor nerve terminals. J Neurosci 12:363-375.

Blanquet PR (2000) Casein kinase 2 as a potentially important enzyme in the nervous system. Prog Neurobiol 60:211-246.

Brodin L, Low P, Shupliakov O (2000) Sequential steps in clathrinmediated synaptic vesicle endocytosis. Curr Opin Neurobiol 10:312-320.

Cremona O, De Camilli P (1997) Synaptic vesicle endocytosis. Curr Opin Neurobiol 7:323-330.

Cremona O, De Camilli P (2001) Phosphoinositides in membrane traffic at the synapse. J Cell Sci 114:1041-1052.

Cockcroft S, De Matteis MA (2001) Inositol lipids as spatial regulators of membrane traffic. J Membr Biol 180:187-194.

Congar P, Trudeau LE (2002) Perturbation of synaptic vesicle delivery during neurotransmitter release triggered independently of calcium influx. J Physiol (Lond) 542:779-793.

Davies SP, Reddy H, Caivano M, Cohen P (2000) Specificity and mech- 
anism of action of some commonly used protein kinase inhibitors. Biochem J 351:95-105.

Davletov B, Sontag JM, Hata Y, Petrenko AG, Fykse EM, Jahn R, Südhof TC (1993) Phosphorylation of synaptotagmin I by casein kinase II. J Biol Chem 268:6816-6822.

Delalande C, Belle R, Cormier P, Mulner-Lorillon O (1999) Transient increase of a protein kinase activity identified to CK2 during sea urchin development. Biochem Biophys Res Commun 266:425-431.

DiAntonio A, Parfitt KD, Schwarz TL (1993) Synaptic transmission persists in synaptotagmin mutants of Drosophila. Cell 73:1281-1290.

Doherty P, Hawgood BJ, Smith IC (1986) Changes in miniature endplate potentials due to moderate hypertonicity at the frog neuromuscular junction. J Physiol (Lond) 376:1-11.

Domin J, Gaidarov I, Smith ME, Keen JH, Waterfield MD (2000) The class II phosphoinositide 3-kinase PI3K-C2alpha is concentrated in the trans-Golgi network and present in clathrin-coated vesicles. J Biol Chem 275:11943-11950.

Fatt P, Katz B (1952) Spontaneous subthreshold activity at motor nerve endings. J Physiol (Lond) 117:109-128.

Foster LJ, Yeung B, Mohtashami M, Ross K, Trimble WS, Klip A (1998) Binary interactions of the SNARE proteins syntaxin-4, SNAP23, and VAMP-2 and their regulation by phosphorylation. Biochemistry 37:11089-11096.

Gaidarov I, Keen JH (1999) Phosphoinositide-AP-2 interactions required for targeting to plasma membrane clathrin-coated pits. J Cell Biol 146:4755-4764.

Gaidarov I, Chen Q, Falck JR, Reddy KK, Keen JH (1996) A functional phosphatidylinositol 3,4,5-trisphosphate/phosphoinositide binding domain in the clathrin adaptor AP-2 alpha subunit: implications for the endocytic pathway. J Biol Chem 271:20922-20929.

Gaidarov I, Smith ME, Domin J, Keen JH (2001) The class II phosphoinositide 3-kinase $\mathrm{C} 2$ alpha is activated by clathrin and regulates clathrin-mediated membrane trafficking. Mol Cell 7:443-449.

Geppert M, Südhof TC (1998) RAB3 and synaptotagmin: the yin and yang of synaptic membrane fusion. Annu Rev Neurosci 21:75-95.

Hao W, Tan Z, Prasad K, Reddy KK, Chen J, Prestwich GD, Falck JR, Shears SB, Lafer EM (1997) Regulation of AP-3 function by inositides: identification of phosphatidylinositol 3,4,5-trisphosphate as a potent ligand. J Biol Chem 272:6393-6398.

Hawgood BJ, Smith IC, Strong PN (1988) Early induction by crotoxin of biphasic frequency changes and giant miniature endplate potentials in frog muscle. Br J Pharmacol 94:765-772.

Heinonen E, Jansson SE, Tolppanen EM (1982) Independent release of supranormal acetylcholine quanta at the rat neuromuscular junction. Neuroscience 7:21-24.

Heuser JE (1974) Proceedings: a possible origin of the "giant" spontaneous potentials that occur after prolonged transmitter release at frog neuromuscular junctions. J Physiol (Lond) 239:106P-108P.

Heuser JE, Reese TS (1973) Evidence for recycling of synaptic vesicle membrane during transmitter release at the frog neuromuscular junction. J Cell Biol 57:315-344

Hidalgo P, Garretón V, Berríos CG, Ojeda H, Jordana X, Holuigue L (2001) A nuclear casein kinase 2 activity is involved in early events of transcriptional activation induced by salicylic acid in tobacco. Plant Physiol 125:396-405.

Hilfiker S, Pieribone VA, Nordstedt C, Greengard P, Czernik AJ (1999) Regulation of synaptotagmin I phosphorylation by multiple protein kinases. J Neurochem 73:921-932.

Hirling H, Scheller RH (1996) Phosphorylation of synaptic vesicle proteins: modulation of the alpha SNAP interaction with the core complex. Proc Natl Acad Sci USA 93:11945-11949.

Hubbard JI, Jones SF, Landau EM (1968) An examination of the effects of osmotic pressure changes upon transmitter release from mammalian motor nerve terminals. J Physiol (Lond) 197:639-657.

Jan LY, Jan YN (1976) Properties of the larval neuromuscular junction in Drosophila melanogaster. J Physiol (Lond) 262:189-214.

Joly M, Kazlauskas A, Corvera S (1995) Phosphatidylinositol 3-kinase activity is required at a postendocytic step in platelet-derived growth factor receptor trafficking. J Biol Chem 270:13225-13230.

Kashani AH, Chen BM, Grinnell AD (2001) Hypertonic enhancement of transmitter release from frog motor nerve terminals: $\mathrm{Ca}^{2+}$ independence and role of integrins. J Physiol (Lond) 530:243-252.

Kim SJ, Kahn CR (1997) Insulin stimulates p70 S6 kinase in the nucleus of cells. Biochem Biophys Res Commun 234:681-685.

Littleton JT, Bellen HJ (1995) Synaptotagmin controls and modulates synaptic-vesicle fusion in a $\mathrm{Ca}^{2+}$-dependent manner. Trends Neurosci 18:4177-4183

Littleton JT, Stern M, Schulze K, Perin M, Bellen HJ (1993) Mutational analysis of Drosophila synaptotagmin demonstrates its essential role in $\mathrm{Ca}^{2+}$-activated neurotransmitter release. Cell 74:1125-1134.

Littleton JT, Stern M, Perin M, Bellen HJ (1994) Calcium dependence of neurotransmitter release and rate of spontaneous vesicle fusions are altered in Drosophila synaptotagmin mutants. Proc Natl Acad Sci USA 91:10888-10892.
Loewen CA, Mackler JM, Reist NE (2001) Drosophila synaptotagmin I null mutants survive to early adulthood. Genesis 31:30-36.

Martys JL, Wjasow C, Gangi DM, Kielian MC, McGraw TE, Backer JM (1996) Wortmannin-sensitive trafficking pathways in Chinese hamster ovary cells: differential effects on endocytosis and lysosomal sorting. J Biol Chem 271:10953-10962.

Meggio F, Shugar D, Pinna LA (1990) Ribofuranosyl-benzimidazole derivatives as inhibitors of casein kinase-2 and casein kinase-1. Eur J Biochem 187:89-94.

Miller TM, Heuser JE (1984) Endocytosis of synaptic vesicle membrane at the frog neuromuscular junction. J Cell Biol 98:685-698.

Molenaar PC, Oen BS, Polak RL (1987) Effect of chloride ions on giant miniature end-plate potentials at the frog neuromuscular junction. J Physiol (Lond) 383:143-152

Molgo J, Pecot-Dechavassine M (1988) Effects of carbonyl cyanide $m$-chlorophenylhydrazone on quantal transmitter release and ultrastructure of frog motor nerve terminals. Neuroscience 24:695-708.

Murthy VN, Stevens CF (1998) Synaptic vesicles retain their identity through the endocytic cycle. Nature 392:497-501.

Naves LA, Van der Kloot W (2001) Repetitive nerve stimulation decreases the acetylcholine content of quanta at the frog neuromuscular junction. J Physiol (Lond) 532:637-647.

Nielander HB, Onofri F, Valtorta F, Schiavo G, Montecucco C, Greengard P, Benfenati F (1995) Phosphorylation of VAMP/synaptobrevin in synaptic vesicles by endogenous protein kinases. $\mathrm{J}$ Neurochem $65: 1712-1720$.

Norris FA, Ungewickell E, Majerus PW (1995) Inositol hexakisphosphate binds to clathrin assembly protein 3 (AP-3/AP180) and inhibits clathrin cage assembly in vitro. J Biol Chem 270:214-217.

Odorizzi G, Babst M, Emr SD (1998) Fab1p PtdIns(3)P 5-kinase function essential for protein sorting in the multivesicular body. Cell 95:847-858.

Peng YY, Zucker RS (1993) Release of LHRH is linearly related to the time integral of presynaptic $\mathrm{Ca}^{2+}$ elevation above a threshold level in bullfrog sympathetic ganglia. Neuron 10:465-473.

Powis G, Bonjouklian R, Berggren MM, Gallegos A, Abraham R, Ashendel C, Zalkow L, Matter WF, Dodge J, Grindey G (1994) Wortmannin, a potent and selective inhibitor of phosphatidylinositol-3kinase. Cancer Res 1994 54:2419-2423.

Rapoport I, Miyazaki M, Boll W, Duckworth B, Cantley LC, Shoelson S, Kirchhausen T (1997) Regulatory interactions in the recognition of endocytic sorting signals by AP-2 complexes. EMBO J 16:2240-2250.

Reist NE, Buchanan J, Li J, DiAntonio A, Buxton EM, Schwarz TL (1998) Morphologically docked synaptic vesicles are reduced in synaptotagmin mutants of Drosophila. J Neurosci 18:7662-7673.

Richards DA, Betz WJ (2000) A possible link between phosphatidylinositol signaling and the actin cytoskeleton in synaptic vesicle cycling at the frog neuromuscular junction. Soc Neurosci Abstr 26:886.

Richards DA, Guatimosim C, Betz WJ (2000) Two endocytic recycling routes selectively fill two vesicle pools in frog motor nerve terminals. Neuron 27:551-559.

Risinger C, Bennett MK (1999) Differential phosphorylation of syntaxin and synaptosome-associated protein of $25 \mathrm{kDa}$ (SNAP-25) isoforms. J Neurochem 72:614-624.

Rosenmund C, Stevens CF (1996) Definition of the readily releasable pool of vesicles at hippocampal synapses. Neuron 16:1197-1207.

Salh B, Wagey R, Marotta A, Tao JS, Pelech S (1998) Activation of phosphatidylinositol 3-kinase, protein kinase B, and p70 S6 kinases in lipopolysaccharide-stimulated Raw 264.7 cells: differential effects of rapamycin, Ly294002, and wortmannin on nitric oxide production. J Immunol 161:6947-6954.

Schiavo G, Gu QM, Prestwich GD, Sollner TH, Rothman JE (1996) Calcium-dependent switching of the specificity of phosphoinositide binding to synaptotagmin. Proc Natl Acad Sci USA 93:13327-13332.

Sciancalepore M, Savic N, Gyori J, Cherubini E (1998) Facilitation of miniature GABAergic currents by ruthenium red in neonatal rat hippocampal neurons. J Neurophysiol 80:2316-2322.

Sellin LC, Molgo J, Tornquist K, Hansson B, Thesleff S (1996) On the possible origin of giant or slow-rising miniature end-plate potentials at the neuromuscular junction. Pflügers Arch 431:325-334.

Spiro DJ, Boll W, Kirchhausen T, Wessling-Resnick M (1996) Wortmannin alters the transferrin receptor endocytic pathway in vivo and in vitro. Mol Biol Cell 7:355-367.

Stein RC, Waterfield MD (2000) PI3-kinase inhibition: a target for drug development? Mol Med Today 6:347-357.

Stenmark H, Aasland R (1999) FYVE-finger proteins: effectors of an inositol lipid. J Cell Sci 112:4175-4183.

Stevens CF, Tsujimoto T (1995) Estimates for the pool size of releasable quanta at a single central synapse and for the time required to refill the pool. Proc Natl Acad Sci USA 92:846-849.

Südhof CT (2001) $\alpha$-Latrotoxin and its receptors: neurexins and CIRL/ latrophilins. Annu Rev Neurosci 24:933-962.

Szyszka R, Grankowski N, Felczak K, Shugar D (1995) Halogenated benzimidazoles and benzotriazoles as selective inhibitors of protein 
kinases CK I and CK II from Saccharomyces cerevisiae and other sources. Biochem Biophys Res Commun 208:418-424.

Takei K, Mundigl O, Daniell L, De Camilli P (1996) The synaptic vesicle cycle: a single vesicle budding step involving clathrin and dynamin. J Cell Biol 133:1237-1250.

Trudeau LE, Doyle RT, Emery DG, Haydon PG (1996) Calciumindependent activation of the secretory apparatus by ruthenium red in hippocampal neurons: a new tool to assess modulation of presynaptic function. J Neurosci 16:46-54

Tsang CW, Elrick DB, Charlton MP (2000) $\alpha$-Latrotoxin releases calcium in frog motor nerve terminals. J Neurosci 20:8685-8692.

Tuazon PT, Traugh JA (1991) Casein kinase I and II: multipotential serine protein kinases: structure, function, and regulation. Adv Second Messenger Phosphoprotein Res 23:123-164.

Van der Kloot W, Colasante C, Cameron R, Molgo J (2000) Recycling and refilling of transmitter quanta at the frog neuromuscular junction. J Physiol (Lond) 523:247-258.

Vautrin J, Kriebel ME (1991) (1991) Characteristics of slow-miniature endplate currents show a subunit composition. Neuroscience 41:71-88.

Vautrin J, Kriebel ME (1997) Giant and sub-miniature end-plate potentials. Pflügers Arch 433:669-670.

Vlahos CJ, Matter WF, Hui KY, Brown RF (1994) A specific inhibitor of phosphatidylinositol 3-kinase, 2-(4-morpholinyl)-8-phenyl-4H-1benzopyran-4-one (LY294002). J Biol Chem 269:5241-5248.

von Poser C, Zhang JZ, Mineo C, Ding W, Ying Y, Südhof TC, Anderson
RG (2000) Synaptotagmin regulation of coated pit assembly. J Biol Chem 275:30916-30924.

Walker EH, Pacold ME, Perisic O, Stephens L, Hawkins PT, Wymann MP, Williams RL (2000) Structural determinants of phosphoinositide 3-kinase inhibition by wortmannin, LY294002, quercetin, myricetin, and staurosporine. Mol Cell 6:909-919.

Wiedemann C, Cockcroft S (1998) Vesicular transport: sticky fingers grab a lipid. Nature 394:426-427.

Wu LG, Betz WJ (1996) Nerve activity but not intracellular calcium determines the time course of endocytosis at the frog neuromuscular junction. Neuron 17:769-779.

Wurmser AE, Gary JD, Emr SD (1999) Phosphoinositide 3-kinases and their FYVE domain-containing effectors as regulators of vacuolar/lysosomal membrane trafficking pathways. J Biol Chem 274:9129-9132.

Wymann MP, Bulgarelli-Leva G, Zvelebil MJ, Pirola L, Vanhaesebroeck B, Waterfield MD, Panayotou G (1996) Wortmannin inactivates phosphoinositide 3-kinase by covalent modification of Lys-802, a residue involved in the phosphate transfer reaction. Mol Cell Biol 16:1722-1733.

Zandomeni R, Zandomeni MC, Shugar D, Weinmann R (1986) Casein kinase type II is involved in the inhibition by 5,6-dichloro-1-beta-Dribofuranosylbenzimidazole of specific RNA polymerase II transcription. J Biol Chem 261:3414-3419. 